\title{
The Impact of Brexit on Pharmaceuticals and HTA
}

\author{
Paula K Lorgelly ${ }^{1}$
}

Published online: 20 March 2018

(C) The Author(s) 2018

We are living in uncertain times. The exit of the United Kingdom (UK) from the European Union (EU) (hereafter, Brexit) will have significant impacts on the health care system, life sciences and the pharmaceutical industry. Health technology assessment (HTA) will not go unaffected. The cost of medicines and health care more generally will increase, the role of the National Institute for Health and Care Excellence (NICE) as a leading global HTA agency could be challenged, and the evidence base with which we do HTA will be impacted. This editorial discusses these issues and attempts to find some opportunities amongst the challenges that HTA faces post-Brexit.

\section{Uncertain Times}

Many health economists have written about uncertainty and its impact on HTA [1-3], but few have written in the face of uncertainty. Brexit has created one of the most uncertain times in the UK across a number of industries and sectors, including the pharmaceutical industry.

As I write this much is known although little is agreed about the details of the UK's exit from the EU. It is likely that the UK will leave the single market and its associated free movement of goods and people, although as the UK is still in the early stages of negotiations with the EU nothing is certain (for example, February 2018 saw Labour moot

Paula K Lorgelly

plorgelly@ohe.org

1 Office of Health Economics, 105 Victoria Street, London SW1E 6QT, UK $a$ customs union and the EU propose a 'common regulatory area' on the island of Ireland, effectively keeping Northern Ireland in the customs union). Changes are already taking place in the pharmaceutical sector due to this uncertainty, particularly the prospect of 'no deal' [4]; below I set out a number of the issues that could arise post-Brexit with respect to the HTA of pharmaceuticals for adoption and reimbursement in the UK National Health Service (NHS), as well as possible wider global implications. It is acknowledged that this is but a minor issue in the context of the effect of Brexit on health and the health care system $[5,6]$, but it is an area in which a significant number of UK health economists specialise, thus is relevant to the discipline [7].

\section{Health Care Will Cost More}

Depending on the extent to which the UK is involved in the EU's public health activities after Brexit [particularly the relationship with the European Medicines Agency, (EMA), see below], pharmaceutical companies (as a minimum) may need to set up a base in both the UK and the EU to test and release batches [8]; for some this could involve moving their EU headquarters from the UK [4]. There will be an additional level of licensure and of regulatory requirements. These will add to pharmaceutical companies' cost base, increasing the cost of producing pharmaceuticals. Likewise, if the UK is not a member of the EMA, then the Medicines and Healthcare products Regulatory Agency (MHRA) would either have to duplicate the function or (more unlikely) adopt the EMA decisions. The MHRA is a 
significant contributor to the EMA, undertaking, amongst other activities, $40 \%$ of all testing and amassing a third of their income by delivering EMA contracts. The loss of this work to other Member States will result in a loss of income to the MHRA. Some of this will be picked up with an increase in the workload due to non-cooperation with the EMA; under a fee-for-service system, this would further increase the cost of supplying medicines in the UK [9].

The extent of various trade deals and the possible imposition of customs duties and changes in the supply chain will also add to the cost of production. Under perfect competition, cost increases would be passed on to the purchaser, either just in the UK or globally, whilst a monopoly supplier would absorb some of the costs. More of an issue is that as the cost of doing business increases in a small country, where prices cannot rise as they are constrained by the likes of the Pharmaceutical Price Regulation Scheme (PPRS), companies will relocate and reconsider their supply.

A departure from the single market will also significantly impact parallel trade. Currently with parallel trade, if third parties can purchase branded medicines in the rest of the EU at lower prices, they can then resell for a profit in the UK at a lower price than others in the UK market. Parallel trade has been shown to lower the cost of pharmaceutical prices [10]; thus without access to such a trade environment, health care costs could increase. The Healthcare Distribution Association estimates that parallel trade directly saved the NHS €986.2 million during the period 2004-2009 [11]. There are also further issues with respect to medicines shortages, which may have long run health effects and associated costs. For a discussion of those issues see Maignen et al. [12].

Higher costs will not be easily absorbed into the NHS; the now infamous Vote Leave’s campaign slogan that $£ 350$ million a week will be returned to the NHS upon leaving the EU will not happen. The health (and social care) budget is already pushed to breaking. There are also supply side consequences; EU migrant staff, particularly in social care, are already leaving [13].

\section{The UK Will Not Be an Early Launch Market}

The UK has traditionally been an early launch market for pharmaceuticals, partly because UK prices are often used as a reference price for other countries [14] and also because NICE assessments are held in high esteem. Brexit could change this. If the UK does not collaborate with the EMA, that is the UK does not accept the marketing authorisation approval of the EMA, then access to the UK market will require an additional authorisation process (and expense) via the MHRA. The fact that the UK market is a mere $2.4 \%$ of global pharmaceutical sales (compared with $21.5 \%$ for all of Europe) (IMS World Review Analyst
2017), coupled with the fourth hurdle of NICE approval, may deter the industry. Further magnifying this is the proposal that NICE charge for its technology appraisal (TA) and highly specialised technologies (HST) guidance as a cost-recovery model [15], although this has been temporarily suspended in light of the other issues that need to be addressed in a life sciences strategy with respect to Brexit. The growing influence of NHS England in adoption decisions, via the budget threshold assessment, also does not incentivise early launch in the UK market $[16,17]$.

\section{NICE to Become Less Relevant?}

It was recently announced that the EMA will move from London to Amsterdam, providing medicines regulation and approval for Europe from temporary accommodation as of the 30th of March 2019. The relocation of the EMA to Amsterdam is particularly significant as the Netherlands has a robust HTA system [18, 19].

Both NICE and its Dutch counterpart [the National Health Care Institute, Zorginstituut Nederland (ZiN)] were lead partners in founding the European Network for Health Technology Assessment (EUnetHTA). ZiN now provides the secretariat for EUnetHTA, which is well established. It was announced in July 2017 that the EMA and EUnetHTA will provide parallel advice to support decision making on marketing authorisation and reimbursement [20]. This parallel consultation will be via either an individual route (with individual country HTA agencies) or a consolidated route \{with the HTA Early Dialogue Working Party (EDWP), which currently includes NICE [21]\}. It is unclear if NICE will continue to take part in this parallel process (and specifically the EDWP), despite being involved in the initial pilots of parallel advice and having a history of successful scientific advice and parallel advice with the MHRA. While membership of EUnetHTA is not dictated by a country's membership in the EU, if the UK decides not to adopt the EMA decisions, any involvement in EUnetHTA could be of limited benefit. More recently, the European Commission also proposed to strengthen cooperation in HTA in the EU, suggesting new regulations for common European HTA methods, sharing data and expertise, and common procedures across the EU [22]. As the UK will not be an EU Member State, NICE and the other HTA agencies in the UK [the Scottish Medicines Consortium (SMC) and the All Wales Medicines Strategy Group (AWMSG)] will have a limited role to play in this new strategy.

It is important to reflect on the changing environment of HTA globally and the influence of NICE. NICE still subscribes-as it has for the last 20 years-to its cost per quality-adjusted life year (QALY) approach with a focus on the health care perspective. Other agencies like $\mathrm{ZiN}$ 
have, arguably, been more innovative in reviewing and changing their guidelines [23], while multi-criteria decision analysis (MCDA) [24, 25] and value frameworks [26] highlight that there is more to HTA than an incremental cost-effectiveness ratio (ICER). NICE is well aware of this, but constrained by NHS England and the Department of Health in making significant change.

\section{The Evidence Base Will Change}

Many of us in research will be acutely aware of the uncertainty that Brexit has had on research funding, and specifically the UK's eligibility and access to programmes like Horizon 2020 and the Innovative Medicines Initiative (IMI), which have been particularly supportive of research in health economics. If such programmes continue with limited UK involvement, then the applicability of project outcomes to the UK setting and the generalisability and transferability of these results could find the UK lagging behind other EU countries when it comes to trialling and adopting new methodologies and research techniques. The knowledge exchange between the UK and the EU is mutually beneficial [27], and is important for supporting the (social) science base.

Clinical trial research will be particularly affected by leaving the EU. Leave campaigners argued that the EU Clinical Trials Directive (EC) No. 2001/20/EC damaged medical research and innovation in the UK as it increased the administrative burden and cost of running trials, which saw a reduction in trials taking place in Europe. The new Clinical Trials Regulation 536/2014 will harmonise the application and authorisation processes. Sponsors will be required to register trials, and there will be greater transparency and an accessible database of results. Implementation of the regulation has been delayed until after March 2019 and will therefore not be captured in the European Union (Withdrawal) Bill (previously known as the Great Repeal Bill), so it is unclear what new legislation would look like. Ideally it would allow the UK to fully participate in the EU system; low standards would not attract the pharmaceutical industry who require trials to meet Food and Drug Administration (FDA) or EMA requirements. Under a scenario of limited cooperation, a pharmaceutical company would register their trial in the EU, which would give them access to all EU countries, but should they wish to recruit UK patients, they would need to seek additional authorisation in the UK. A reduction in the number of UK patients in trials means British patients will not get to benefit from these innovations early, and the evidence base that is submitted for marketing authorisation and market access may not be representative of the UK patient population, challenging the validity of the HTA outcome.
Brexit will also affect the evidence base in terms of data, both data sharing and data protection. Clinical trial data and other personal data like health records are currently governed by the EU Data Protection Directive and the UK Data Protection Act 1998. As of May 2018, the General Data Protection Regulation EU/2016/679 will come into force. As this is a regulation, it will need to be legislated for when the UK leaves the EU, which could introduce some changes. A significant issue for HTA could be the sharing of data once the UK leaves the EU. The 1998 Act states that "personal data shall not be transferred outside the European Economic Area unless there is adequate protection'. This could cause problems for not just clinical trial data but also real world evidence (RWE). RWE is gaining traction in HTA [19], and the UK as a post-launch study site to collect such data could become less attractive. An additional issue with data sharing is the EMA's role in monitoring the safety and efficacy of pharmaceuticals. If there was limited cooperation between the UK/MHRA and the EMA, which is additionally hindered by constraints around data sharing, then patient safety and public health would be at risk [12].

\section{Possible Opportunities}

Every cloud has a silver lining, but in truth it is difficult to find the opportunities for HTA in Brexit. The UK market could be promoted to industry by offering early engagement and a fast-track stream-lined MHRA and NICE parallel approval process. The HTA process could become value-led, specifically involving NHS England in discussions on access agreements and promote flexible pricing and reimbursement arrangements like outcome-based payments [28] and multi-indication pricing [29]. This, however, will not be affordable without an increase in NHS funding, and necessitates evaluating what such innovations in HTA and market access are worth in terms of patient benefit and a buoyant life sciences industry.

\section{Deal or No Deal}

It is important to point out that while there are many 'deals' to be negotiated, there is a possibility_-given statements from Prime Minister May that 'no deal is better than a bad deal' [30] —-that come March 2019, Britain will not have secured a trade deal with the EU. It will then fall under the World Trade Organization's (WTO) terms. Without a free trade agreement (FTA), tariffs would apply. In addition, important questions over the legality of the FTAs with nonEU countries would need addressing, specifically the grandfathering of trade deals and what implications this has 
on rules of origin [31]. At its worst, it could affect the supply chain of pharmaceuticals, as there may be legal and regulatory gaps in those pharmaceutical regulations that may not be covered by the European Union (Withdrawal) Bill [12].

\section{Final Thoughts}

I suspect some of what I have written above will eventuate in the coming weeks, months and years; I do not wish to take a bet on which scenario will materialise as I lost money on that fateful day in June 2016. However, one can only hope that the Brexit effect on HTA is a short- to medium-term phenomenon, and the strength and growth that the discipline experienced during the UK austerity phase bodes well for this coming experience. As an eminent professor once said to me, 'austerity means that they [the government] need health economists even more to ensure they are getting value for money'. Maybe that will be true of Brexit. Maybe there will be a mass migration of health economists to Canada or indeed for many of us back to our country of birth, be that the continent or further afield. Perhaps, just perhaps, HTA will benefit globally.

Acknowledgements The author would like to thank Adrian Towse and Mike Drummond for discussions and reviews of early drafts. The author would also like to acknowledge the patience of Tim Wrightson for bearing with the author's uncertainty regarding when the right time to finalise the paper was; at times it was like the protracted Brexit negotiations, but hopefully with a better outcome.

\section{Compliance with Ethical Standards}

Funding No funding was received to write this paper.

Conflict of interest The author reports no conflicts of interest; the author voted remain.

Open Access This article is distributed under the terms of the Creative Commons Attribution-NonCommercial 4.0 International License (http://creativecommons.org/licenses/by-nc/4.0/), which permits any noncommercial use, distribution, and reproduction in any medium, provided you give appropriate credit to the original author(s) and the source, provide a link to the Creative Commons license, and indicate if changes were made.

\section{References}

1. Briggs A, Sculpher M, Buxton M. Uncertainty in the economic evaluation of health care technologies: the role of sensitivity analysis. Health Econ. 1994;3(2):95-104.

2. Philips Z, Bojke L, Sculpher M, Claxton K, Golder S. Good practice guidelines for decision-analytic modelling in health technology assessment. Pharmacoeconomics. 2006;24(4):355-71.

3. Eckermann S, Willan AR. Expected value of information and decision making in HTA. Health Econ. 2007;16(2):195-209.
4. The Economist, Pharmaceutical firms trigger contingency plans for a no-deal Brexit. 2017. https://www.economist.com/news/ britain/21731409-industry-long-production-timelines-cannotafford-wait-any-longer-pharmaceutical-firms?fsrc=rss.

5. Dayan M, How will our future relationship with the EU shape the NHS? 2017: Nuffield Trust. http://www.nuffieldtrust.org.uk/ research/brexit-relationship-eu-shape-nhs.

6. Fahy N, Hervey T, Greer S, Jarman H, Stuckler D, Galsworthy M, McKee M. How will Brexit affect health and health services in the UK? Evaluating three possible scenarios. Lancet. 2017;390(10107):2110-8.

7. Kaambwa B, Frew E. Health economics in the UK: capacity, constraints and comparisons to US health economists. Int Rev Econ Educ. 2013;12:1-11.

8. Acha V. Breaking up the band: European regulatory cooperation in a post-Brexit world. Br J Pharm. 2017;2(1):1-5.

9. Hatswell AJ. How do we avoid disaster when exiting the European Medicines Agency? Making the most of Brexit in pharmaceutical regulation. Ecancermedicalscience. 2017;11:ed67.

10. Ganslandt M, Maskus KE. Parallel imports of pharmaceutical products in the European Union. 2001. The World Bank. http:// apps.who.int/medicinedocs/documents/s17518en/s17518en.pdf.

11. Enemark U and Pedersen M, Parallel import of pharmaceuticals in Denmark, Germany, Sweden and the UK, 2004-2009, an analysis of savings. 2011, CAST-Centre for Applied Health Services Research and Technology Assessment Odense: University of Southern Denmark.

12. Maignen F, Berdud M, Hampson G, Lorgelly P. Public health and economic implications of the United Kingdom exiting the EU and the single market. OHE Consulting Report, Office of Health Economics, 2017. https://www.ohe.org/system/files/private/ publications/Executive\%20report\%20-\%20final.pdf.

13. Costa-Font J. The National Health Service at a critical moment: when Brexit means hectic. J Soc Policy. 2017;46(4):783-95.

14. Rémuzat C, Urbinati D, Mzoughi O, El Hammi E, Belgaied W, Toumi M. Overview of external reference pricing systems in Europe. J Mark Access Health Policy. 2015;3(1):27675.

15. National Institute for Health and Care Excellence, Charging for NICE technology appraisal and highly specialised technologies guidance: a document for consideration and comment by the life sciences industries' associations. 2016. https://www. remapconsulting.com/wp-content/uploads/2016/09/NICE-TAand-HST-cost-recovery-for-industry-associations-August-2016FINAL.pdf.

16. Ogden J. How will NICE's budget impact test affect new drug availability? Prescriber. 2017;28(8):9-12.

17. Buckland D. Brexit and the EMA: what's next for the UK? Prescriber. 2017;28(5):49-51.

18. Wilsdon T, Fiz E, Haderi A. A comparative analysis of the role and impact of health technology assessment: 2013. Washington DC: Charles River Associates; 2014.

19. Makady A, van Veelen A, Jonsson P, Moseley O, d'Andon A, De Boer A, Hillege J, Klungel O, Goettsch W. Using real-world data (RWD) in health technology assessment (HTA) practice: a comparative study of 5 HTA agencies. Value Health. 2017;20(9):A401.

20. European Medicines Agency. Parallel consultation with regulators and health technology assessment bodies. 2017 1st February 2018]; Available from: http://www.ema.europa.eu/ema/index. jsp?curl=pages/regulation/general/general_content_001857. jsp\&mid=WC0b01ac0580a11c96.

21. EUnetHTA and EMA, Guidance for parallel consultation, EMA/ 410962/2017. 2017. http://www.ema.europa.eu/docs/en_GB/ document_library/Regulatory_and_procedural_guideline/2017/ 07/WC500230375.pdf. 
22. European Commission, Proposal for a regulation of the European Parliament and of the Council on health technology assessment and amending Directive 2011/24/EU. 2018. https://ec.europa.eu/ health/sites/health/files/technology_assessment/docs/com2018_ 51final_en.pdf.

23. Versteegh M, Knies S, Brouwer W. From good to better: new Dutch guidelines for economic evaluations in healthcare. Pharmacoeconomics. 2016;34(11):1071-74.

24. Thokala P, Devlin N, Marsh K, Baltussen R, Boysen M, Kalo Z, Longrenn T, Mussen F, Peacock S, Watkins J. Multiple criteria decision analysis for health care decision making - an introduction: report 1 of the ISPOR MCDA Emerging Good Practices Task Force. Value Health. 2016;19(1):1-13.

25. Marsh K, IJzerman M, Thokala P, Baltussen R, Boysen M, Kaló Z, Lönngren T, Mussen F, Peacock S, Watkins J. Multiple criteria decision analysis for health care decision making-emerging good practices: report 2 of the ISPOR MCDA Emerging Good Practices Task Force. Value health. 2016;19(2):125-37.

26. Garrison LP, Neumann PJ, Willke RJ, Basu A, Danzon PM, Doshi JA, Drummond MF, Lakdawalla DN, Pauly MV, Phelps CE. A health economics approach to US value assessment frameworks-summary and recommendations of the ISPOR Special Task Force report [7]. Value Health. 2018;21(2):161-5.
27. Varnai P, Rentel M, Davé A, De Scalzi M, Timmerman W, Rosemberg-Montes C, Simmonds P. The impact of collaboration: the value of UK medical research to EU science and health 2017. Technopolis Group. http://www.cancerresearchuk.org/about-us/ we-develop-policy/we-work-with-government/exiting-the-eu/ukand-eu-research.

28. Carlson JJ, Sullivan SD, Garrison LP, Neumann PJ, Veenstra DL. Linking payment to health outcomes: a taxonomy and examination of performance-based reimbursement schemes between healthcare payers and manufacturers. Health Policy. 2010;96(3):179-90.

29. Persson U, Norlin J. Multi-indication and combination pricing and reimbursement of pharmaceuticals: opportunities for improved health care through faster uptake of new innovations. Appl Health Econ Health Policy. 2018. Feb 22. https://doi.org/10. 1007/s40258-018-0377-7.

30. Prime Minister's Office. The government's negotiating objectives for exiting the EU: PM Speech. 2017 17th January 2017; Available from: https://www.gov.uk/government/speeches/thegovernments-negotiating-objectives-for-exiting-the-eu-pmspeech.

31. Holmes P, Rollo J, Winters LA. Negotiating the UK's post-Brexit trade arrangements. Natl Inst Econ Rev. 2016;238(1):R22-30. 